\title{
SGLT-2 Inhibitors in Heart Failure and Type-2 Diabetes: Hitting Two Birds with One Stone?
}

\author{
Diogo Santos-Ferreira ${ }^{a, b}$ Pedro Gonçalves-Teixeira ${ }^{a, b}$ \\ Ricardo Fontes-Carvalho ${ }^{a, b}$

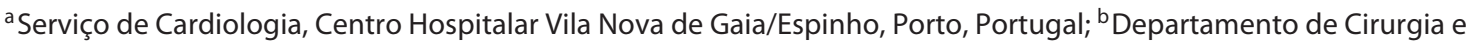 \\ Fisiologia, Unidade de Investigação Cardiovascular, Faculdade de Medicina da Universidade do Porto, \\ Porto, Portugal
}

\section{Keywords}

Diabetes mellitus - Type 2 diabetes mellitus - Diabetic cardiomyopathies $\cdot$ Heart failure $\cdot$ Chronic heart failure . Preventive cardiology · Sodium-glucose transporter 2 inhibitors

\section{Abstract \\ Type 2 diabetes mellitus (T2DM) and heart failure (HF) have a tremendous impact worldwide, markedly reducing life-ex- pectancy and quality of life. It is now known that each dis- ease represents a risk factor for the other. Moreover, when they are combined, the prognosis is significantly worse. Un- til recently, these pathologies have been managed indepen- dently. However, their treatment paradigm is rapidly chang- ing, with recent cardiovascular outcome trials showing that sodium-glucose cotransporter-2 inhibitors (SGLT-2i) are ef- fective in the management of both diseases. This article ex- plores the interactions between T2DM and HF and the con- cept of diabetic cardiomyopathy and summarizes recent data regarding the effects of SGLT-2i on HF hospitalization and the proposed pathophysiological mechanisms involved.}

(c) 2019 S. Karger AG, Basel

\section{Introduction}

It is estimated that 1 in every 11 adults has diabetes mellitus (DM), and the number is increasing for multiple reasons, such as ageing of the population, economic development, urbanization, and unhealthy lifestyles. Over $90 \%$ of cases are of type 2 DM (T2DM) [1]. Although the most paradigmatic consequence of T2DM is a chronic hyperglycemic state, cardiovascular complications are responsible for most of the mortality associated with the disease [1]. More recent studies have also shown that heart failure (HF) is the second most common initial cardiovascular manifestation in T2DM patients [2], highlighting the importance of this interaction.

In 2008, the US Food and Drug Administration required that all commercialized glucose-lowering drugs demonstrate cardiovascular safety [3]. This led to the development of dozens of cardiovascular outcome clinical trials which provided significant new data to improve our understanding of the relation between T2DM and cardiovascular disease. Moreover, they showed that sodiumglucose cotransporter-2 inhibitors (SGLT-2i) and some glucagon-like peptide-1 receptor agonists could significantly reduce the risk of cardiovascular events, changing the landscape of T2DM treatment. Instead of an exclu-

Ricardo Fontes-Carvalho

Departamento de Cirurgia e Fisiologia, Unidade de Investigação Cardiovascular Faculdade de Medicina da Universidade do Porto PT-4200-319 Porto (Portugal)

E-Mail fontes.carvalho@gmail.com 
sively "glucocentric approach," T2DM management should rather contemplate the use of strategies that can reduce the risk of cardiovascular (and renal) events, including these new drugs and integrated control of all cardiovascular risk factors.

This article aims to review the interaction between T2DM and HF and the concept of diabetic cardiomyopathy and to summarize recent data regarding the effects of SGLT-2i on HF hospitalization (HHF) and the proposed pathophysiological mechanisms involved.

\section{The Interaction between T2DM and HF: the Concept of Diabetic Cardiomyopathy}

Diabetic cardiomyopathy is defined as the presence of diastolic or systolic dysfunction in a patient with DM without other obvious causes of cardiomyopathy, such as coronary artery disease, hypertension, or valvular heart disease [4-6]. It is initially characterized by myocardial fibrosis and dysfunctional remodeling and associated diastolic dysfunction, followed by systolic dysfunction and, eventually, clinical HF [6].

DM represents an important risk factor for the development of HF, with a relative risk of 1.82 and 3.75 over 2 years in men and women with diabetes, respectively [7]. In fact, T2DM patients have about a 2.5 times higher risk of developing HF than nondiabetes patients, with younger patients being at the greatest risk [8]. This appears to be, at least in part, glycemic dependent because each $1 \%$ increase in glycated hemoglobin (HbAlc) is associated with an $8 \%$ increased risk of HF [9]. Additionally, in the UKPDS study, a $1 \%$ reduction of $\mathrm{HbAlc}$ was associated with a $16 \%$ reduction of the risk of developing HF [10]. Even in non-DM patients, for every increase of $18 \mathrm{mg} / \mathrm{dL}$ in fasting plasma glucose there is an increase of 1.23 times in HHF [11]. Interestingly, and adding more complexity to the data, subclinical changes in diastolic function are observed even before the onset of diabetes, and they are mainly associated with the state of insulin resistance [12]. As a result, the prevalence of DM in patients hospitalized for HF can be as high as $44 \%$ [13].

Likewise, HF also acts as a risk factor for T2DM, as its incidence in HF studies is more than twice that in the general population [4]. The prevalence of HF in patients with T2DM is about $10-23 \%$, i.e., 3 times higher than in nondiabetes control groups $[14,15]$. One of the explanations for this is based on p53-induced adipose tissue inflammation through chronic pressure overload and insulin resistance [16].
The clinical outcomes associated with HF are considerably worse for patients with DM [6], with a median survival of 4 years [17]. Therefore, patients with a simultaneous diagnosis of T2DM and HF represent a significant subpopulation that should receive therapies proven to be effective under those conditions.

Several pathophysiological mechanisms have been implicated in the onset of diabetic cardiomyopathy (Fig. 1). Beyond hyperglycemia and its metabolic consequences (such as increased free fatty acids, formation of advanced glycation end products, cytokines, enzymatic O-GlcNAcylation of cardiomyocyte proteins, and impaired cardiac insulin metabolic signaling), other mediators have been implicated, i.e., changes in myocardial metabolism and perfusion (through microvascular dysfunction), oxidative stress, inflammation, autonomic dysfunction, the sympathetic nervous system (SNS), renin-angiotensinaldosterone system (RAAS) activation, reduced nitric oxide bioavailability, endoplasmic reticulum stress, and increased collagen-based cardiomyocyte and extracellular matrix stiffness, resulting in cardiac remodeling, with development and progression of diabetic cardiomyopathy $[5,6,18,19]$. In fact, the decreased cardiomyocyte function may be in part mediated by abnormal cytosolic and mitochondrial calcium handling [5]. Another common denominator between T2DM and HF appears to be stimulation of the sodium-hydrogen exchanger (NHE) in the heart and vasculature (NHE1 isoform) and the kidneys (NH3 isoform) by agents such as norepinephrine, angiotensin, and aldosterone - associated with HF - and insulin, glucose, and certain adipokines - increased in T2DM [20].

\section{SGLT-2i: from Mechanisms of Action to Cardiovascular Outcome Trials}

\section{Glucose-Lowering Effects of SGLT-2i}

Seven isoforms of sodium-glucose cotransporter (SGLT) have been described [21], with 2 most studied to date being SGLT-1 and SGLT-2. SGLT-1 is mainly expressed in the small intestines and in the proximal convoluted tubule of the kidneys, where it is responsible for less than $10 \%$ of filtered glucose reabsorption. SGLT-2 is also expressed in the apical membrane of the proximal convoluted tubule cells and it is responsible for about $90 \%$ of filtered glucose reabsorption, which occurs in a 1:1 stoichiometry of sodium to glucose. In T2DM, SGLT-2 can be upregulated, which intensifies and perpetuates hyperglycemia [22]. SGLT-2i represent a relatively new 


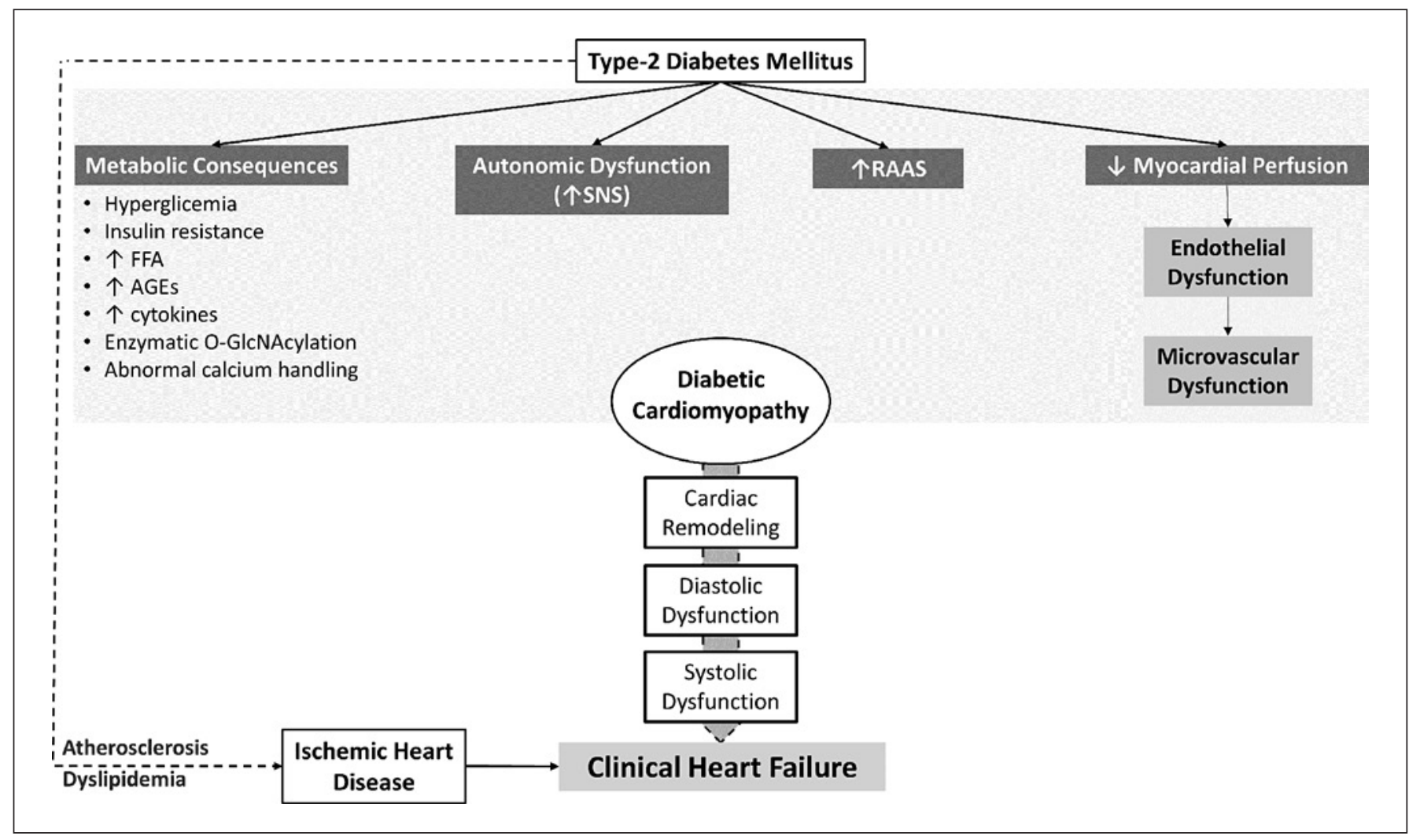

Fig. 1. Mechanisms mediating HF in T2DM patients. FFA, free fatty acids; AGEs, advanced glycation end products.

class of drugs for T2DM; they were approved in the USA and Europe in 2013. Their glucose-lowering effect occurs via an insulin-independent pathway mainly through glucosuria, increasing the urinary excretion of glucose and the fractional excretion of sodium, with modest diuretic and natriuretic effects [4]. It is expected that, with their use, HbA1c will be decreased by about $0.5-1 \%$ [23-25] (IFCC: $5.5-11 \mathrm{mmol} / \mathrm{mol}$ ). Several SGLT-2i, such as dapagliflozin, empagliflozin, ipragliflozin, canagliflozin, tofogliflozin, luseogliflozin, ertugliflozin, and sotagliflozin, are currently available (though some are not yet approved).

\section{Cardiovascular Effects of SGLT-2i: Effects on Major}

\section{Adverse Cardiovascular Events}

Over the last years, 3 important clinical trials have been conducted regarding the cardiovascular safety and benefits of SGLT-2i [4]: the EMPA-REG OUTCOME trial (for 10 or $25 \mathrm{mg}$ of empagliflozin) [26], the CANVAS Program (for 100 or $300 \mathrm{mg}$ of canagliflozin) [27], and DECLARE-TIMI 58 (for $10 \mathrm{mg}$ of dapagliflozin) [28], all performed on T2DM patients. Although these studies focused on different populations (as detailed in Table 1), which may account for the different findings, the combined data suggests that this new class reduces the risk of major adverse cardiovascular events (MACE) - a combined endpoint of death from cardiovascular causes, nonfatal myocardial infarction (MI), or nonfatal stroke - by $14 \%$ in patients with atherosclerotic cardiovascular disease, i.e., there were no differences statistically significant in patients with only multiple risk factors and no cardiovascular disease [29]. There was also a reduction of MI by $15 \%$, of cardiovascular death by $20 \%$, and of all-cause death by $17 \%$, again, only in T2DM patients with established cardiovascular disease [29].

A subgroup analysis of DECLARE-TIMI 58 concluded that, in patients with a prior MI, dapagliflozin reduced the relative risk of MACE by $16 \%$, with a number-needed-totreat (NNT) of 39 over 4 years, without having an effect on patients without a prior MACE. There was a risk reduction of recurrent $\mathrm{MI}$, and it was more pronounced in type 2 MI. The relative risk reductions in cardiovascular 
Table 1. Outcomes of randomized control trials studying SGLT-2i

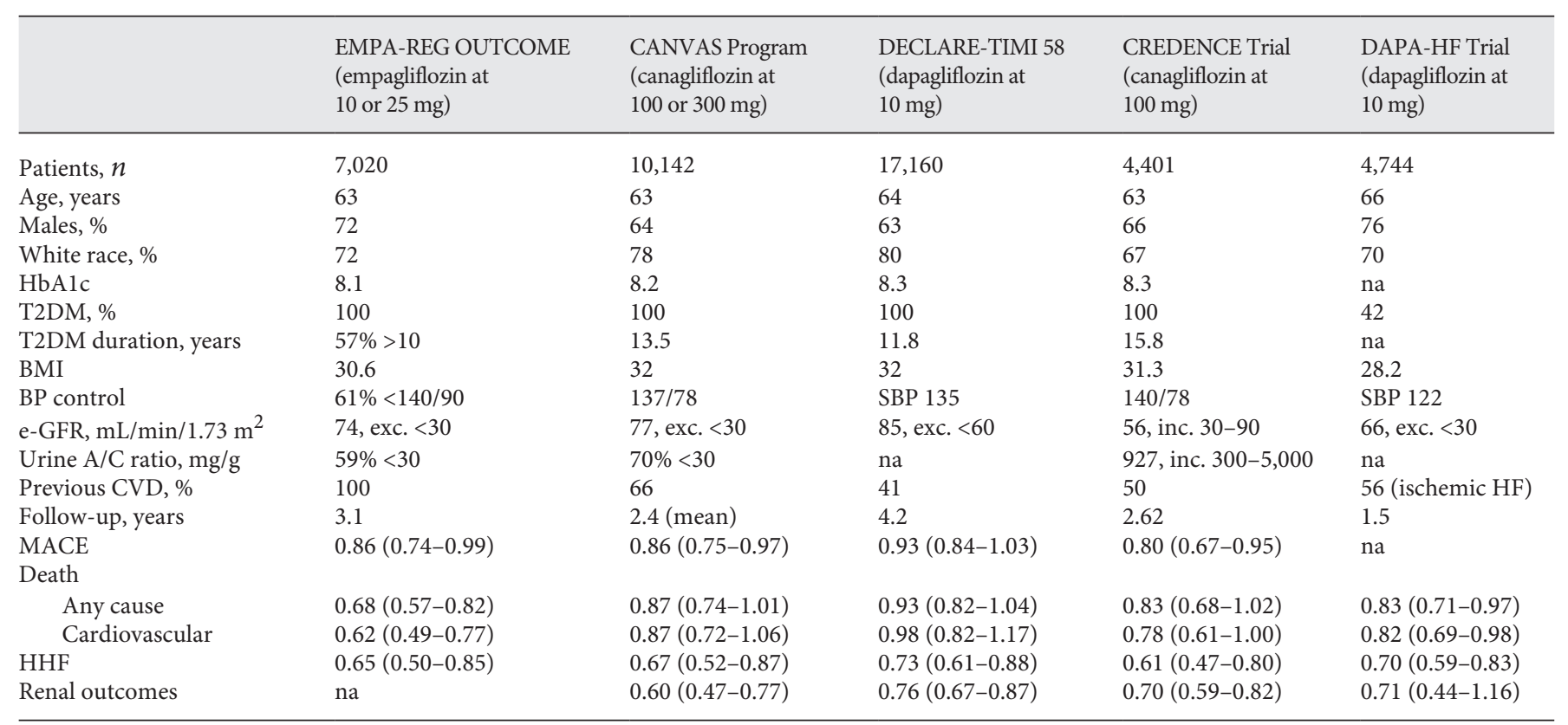

Values are presented as hazard ratio (95\% confidence interval) unless otherwise stated. SBP, systolic blood pressure; A/C, albumin/creatinine; CVD, cardiovascular disease; inc., included; exc., excluded; na, not available.

death/HHF were maintained and similar in both groups, with a higher absolute risk reduction and an NNT of 53 over 4 years in the prior-MI group [30].

\section{Cardiovascular Effects of SGLT-2i: HF Hospitalization}

The most impressive results of SGLT-2i trials were a consistent reduction of $37 \%$ in the risk of HHF, independently of the presence of a history of atherosclerotic cardiovascular disease or multiple risk factors alone or even of preexisting HF or not (i.e., as both primary and as secondary prevention) $[29,31]$. The reduction in the risk of HHF is evident immediately by the first month after initiating SGLT-2i, and it persists throughout the trials' duration [31]. As is known, repeated HHF is a strong predictor of mortality [32] and preventing the former may lower the latter. In fact, a recent meta-analysis showed a combined reduction of $\mathrm{HHF} /$ cardiovascular death of $23 \%$ [29]. Additional data suggests that these agents might halve the post-acute HHF and mortality in the vulnerable phase [33].

The effects of SGLT-2i according to the subtype of HF remain to be established. An interesting subgroup analysis of DECLARE-TIMI 58 compared patients with a known reduced ejection fraction (EF; $<45 \%)(\mathrm{HF}$ with a reduced EF; HFrEF) with subjects with a history of HF without a known EF reduction. Dapagliflozin was able to lower HHF both in the HFrEF group $(\mathrm{HR}=0.64)$ and in the non-HFrEF group $(\mathrm{HR}=0.76)$ [34], which is particularly interesting because there are no specific therapies approved for HF with a preserved EF. This hypothesis is being specifically evaluated in several on-going clinical trials.

The first evidence that SGLT-2i should be used as HF drugs, rather than merely as glucose-lowering agents, was recently shown in DAPA-HF. This trial studied the effect of dapagliflozin $(10 \mathrm{mg}$ ) versus placebo in patients with HF and a reduced EF (below 40\%), including 58\% of nonT2DM patients. There was a $26 \%$ reduction in the primary composite endpoint of worsening HF and cardiovascular death $(\mathrm{NNT}=21)$, with a $30 \%$ reduction in $\mathrm{HHF}$ and a reduction in total mortality. Notably, this benefit was observed independently of the presence of T2DM. The effect was most significant among NYHA class II patients versus class III/IV patients. Its use was safe, even in nonT2DM patients [35].

The benefits of SGLT-2i in HHF have been also demonstrated outside of the clinical trial environment, using data from an unselected population from clinical settings, as detailed in Table 2. For example, the first interim analysis from the EMPRISE study [36] showed a 50\% re- 
Table 2. Outcomes of SGLT-2i observational studies

\begin{tabular}{lllll}
\hline & $\begin{array}{l}\text { EMPRISE } \\
\text { (empagliflozin vs. sitagliptin) }\end{array}$ & $\begin{array}{l}\text { CVD-REAL } \\
\text { (SGLT-2i vs. other GLD) }\end{array}$ & $\begin{array}{l}\text { CVD-REAL NORDIC } \\
\text { (SGLT-2i vs. other GLD) }\end{array}$ & $\begin{array}{l}\text { CVD-REAL 2 } \\
\text { (SGLT-2i vs. other GLD) }\end{array}$ \\
\hline Patients, $n$ & 32,886 & 309,056 & 91,320 & 470,128 \\
Age, years & 59 & 57 & 61 & 57 \\
Males, \% & 54 & 56 & 60 & 55 \\
Previous CVD, \% & 25 & 13 & 25 & 27 \\
Death (any cause) & na & $0.49(0.41-0.57)$ & $0.51(0.45-0.58)$ & $0.51(0.37-0.70)$ \\
HHF & $0.51(0.39-0.68)$ & $0.61(0.51-0.73)$ & $0.70(0.61-0.81)$ & $0.64(0.50-0.82)$ \\
\hline
\end{tabular}

Values are presented as hazard ratio (95\% confidence interval) unless otherwise stated. GLD, glucose-lowering drugs; na, not available.

duction of HF discharge diagnosis in patients who initiated empagliflozin (10 or $25 \mathrm{mg}$ ) versus sitagliptin (a dipeptidyl peptidase- 4 inhibitor) in T2DM patients with or without a history of cardiovascular disease at baseline. Also, CVD-REAL analyzed data from medical claims, primary care/hospital records, and national registries from the USA and Europe and confirmed that the initiation of SGLT-2i versus other glucose-lowering drugs was associated with a lower rate of HHF $(\mathrm{HR}=0.61)$ and allcause death $(\mathrm{HR}=0.49)$. The majority of the patients did not have established cardiovascular disease, suggesting that these benefits in cardiovascular outcomes may be applicable also in primary prevention, which was confirmed by other analyses [37, 38]. A subanalysis demonstrated that there also seems to be a modest reduction of $\mathrm{MI}(\mathrm{HR}=0.85)$ and stroke ( $\mathrm{HR}=0.83)$ [39]. CVD-REAL Nordic was only applied to Denmark, Norway, and Sweden and it found that SGLT-2i initiation was associated with a decreased risk of cardiovascular mortality $(\mathrm{HR}=$ $0.53)$ and all-cause mortality $(\mathrm{HR}=0.51)$, MACE $(\mathrm{HR}=$ $0.78)$, and HHF ( $\mathrm{HR}=0.70)$, without significant differences regarding nonfatal MI, nonfatal stroke, or atrial fibrillation. There was also a decreased risk of severe hypoglycemia $(\mathrm{HR}=0.76)$. The effects were evident irrespectively of existing cardiovascular disease [40]. The CVD-REAL 2 study confirmed, in a community-based population outside the USA and Europe, again through claims, medical records, and national registries, that initiation of an SGLT-2i versus other glucose-lowering drugs was associated with a lower risk of death $(\mathrm{HR}=$ $0.51)$, $\mathrm{HF}(\mathrm{HR}=0.64)$, $\mathrm{MI}(\mathrm{HR}=0.81)$, and stroke $(\mathrm{HR}=0.68)$, which was consistent across countries and patient subgroups and irrespective of previous cardiovascular disease [41]. In both studies, the benefits seemed to be class related.

SGLT-2 Inhibitors in HF and T2DM
Although the SGLT-2i effects on kidney function are not a subject for this review, briefly, the CREDENCE trial (canagliflozin at $100 \mathrm{mg}$ ) showed, in patients with T2DM stage 2-3 chronic kidney disease with albuminuria, a statistically significant $30 \%$ reduction in a composite outcome of end-stage kidney disease, doubling serum creatinine levels, or death from renal or cardiovascular causes. Moreover, HHF was significantly reduced by $39 \%$ [42]. Similar benefits were also shown in the subanalysis of the EMPAREG-OUTCOME, CANVAS Program, and DECLARE-TIMI 58 trials. In conclusion, these data demonstrate that the benefits of SGLT-2i go beyond the metabolic and cardiovascular territories and delay the decline in renal function.

\section{Benefits of SGLT-2i: A Class Effect?}

The joint analyses of all these studies suggest that most of the cardiovascular benefits of SGLT-2i reflect a class effect. However, we cannot rule out that they may vary with the drug used. Investigation has shown that dapagliflozin (and ipragliflozin) may be categorized as longacting SGLT-2i, in contrast to empagliflozin and canagliflozin (besides tofogliflozin and luseogliflozin), as they have an intermediate action [43]. Long-acting SGLT-2i may be more potent, with better glucose control throughout the day and a lower plasma insulin variability, also improving glucose tolerance in T2DM mice and demonstrating a trend towards superiority regarding diabetesrelated complications $[44,45]$. Regarding selectivity for SGLT-2, empagliflozin is the most selective of the 3 , followed by dapagliflozin, with canagliflozin being the least selective [46-48]. Note that SGLT-2i with low SGLT-2/ SGLT-1 selectivity elevate the level of circulating glucagon-like peptide-1 [49], which may contribute to a pleiotropic effect. 


\section{Possible Mechanisms Responsible for SGLT-2i Effects on Cardiovascular Outcomes}

There are several pathophysiological pathways that can mediate the cardiovascular and renal benefits of SGLT-2 inhibition. Although SGLT-2i have a clear glucose-lowering effect, their impact on cardiovascular and renal outcomes is not mediated by the reduction in HbA1c. Importantly, the recent DAPA-HF trial confirmed that the benefits were also observed in the nonT2DM population [35].

It is also interesting to observe that the positive cardiovascular outcomes were not dose dependent. For example, the reduction in the risk of cardiovascular death after initiating empagliflozin was not affected by dosing, baseline $\mathrm{HbAlc}$, or its change throughout the trial $[14,50]$. Additionally, though the glucose-lowering effect of SGLT-2 $\mathrm{i}$ is reduced in patients with chronic kidney disease, the cardiovascular and renal benefits persist in patients with different kidney functions, even with estimated glomerular filtration rates of $30-60 \mathrm{~mL} / \mathrm{min} / 1.73 \mathrm{~m}^{2}$ [51]. This observation suggests that the mechanisms involved in glycemic control and cardiovascular risk reduction are dissociated and/or follow a different dose-response curve [52].

\section{The Hemodynamic Effect of SGLT-2i and the "Smart}

Diuresis" Hypothesis

Several trials have shown that the reduction in HHF is seen almost immediately after starting SGLT-2i, i.e., after just 1 month, which supports the concept that these benefits reflect an improvement in the hemodynamic state. It is believed that SGLT-2i can ameliorate ventricular loading conditions thanks to a preload reduction due to its diuretic and natriuretic effects [52]. In fact, changes in markers of plasma volume (such as increasing hematocrit and hemoglobin) are key mediators in the reduction of cardiovascular death [53].

Some authors have postulated the concept of smart diuresis. It seems that SGLT-2i, unlike loop diuretics, lead to a greater electrolyte-free water clearance, with more fluid clearance from the interstitial fluid space than from circulation and a lower impact on blood volume, arterial filling, and organ perfusion. In fact, though both blood and interstitial fluid volumes are increased in HF, there is a relative arterial underfilling due to a low cardiac output, so it may be more relevant to reduce the interstitial volume than the blood volume [54]. Another important difference from conventional diuretics is that SGLT-2i can lower uric acid serum levels instead of raising them, with- out altering potassium homeostasis or impairing glucose tolerance $[55,56]$.

Furthermore, it is known that SGLT-2i reduce blood pressure (BP), i.e., about $4 / 1.6 \mathrm{~mm} \mathrm{Hg}$ [57] - and alter vascular function, with improvement of endothelial function and aortic stiffness indices [52]. In fact, diuresis is not the only mechanism involved in BP reduction, because this effect is sustained, unlike the increased urinary output, which is temporary and returns to pretreatment levels after 12 weeks $[19,58]$. This lower BP is not followed by an increase in heart rate, unlike vasodilators - suggesting that the SNS is not activated and may even be inhibited [56]. Chronic activation of the SNS has been identified in HF [59] - a higher activation and, consequently, a higher heart rate are associated with an increased risk of microvascular and cardiovascular complications and even death $[60,61]$. The use of luseogliflozin is able to reduce the heart rate; the higher the pre-treatment rate is, the greater its fall is $[62,63]$.

\section{The Metabolic Effect: Changing the Heart Metabolic \\ Substrate}

Another important pathway likely involved in cardiovascular benefits of SGLT-2i is their impact on cardiac metabolism by improving myocardial energetics and substrate efficiency. It is known that this class-drug promotes an increase in ATP production with higher rates of fatty acids and glucose oxidation [64] and ketogenesis. Increasing $\beta$-hydroxybutyrate has been associated with multiple cardiovascular benefits $[19,52,55,65]$. Moreover, SGLT-2i may promote branched-chain amino acid degradation, which is impaired in HF [66].

\section{Other Possible Mechanisms}

Hyperglycemia induces reactive oxygen species production through activation of NOX. This signaling occurs via SMIT1 (an isoform of SGLT) which senses hyperglycemia through SGLT-1. Therefore, the use of SGLT-2i especially those less selective for SGLT-2 with partial inhibition of SGLT-1 - may be responsible for the lower oxidative stress in the myocardium [21,67]. Regarding cardiac fibrosis, it is curious that these drugs may exert antifibrotic effects, with decreased myocardial oxidative stress $[52,68]$. There may also be a reduction in left ventricular (LV) mass index [69]. In prediabetes ob/ob-/mice, empagliflozin improved coronary microvascular function and contractile performance, as well as liver function, steatosis, glycemic status, and lipid profile, with increased nitric oxide production [70]. A study using ipragliflozin showed its ability to prevent LV hypertrophy 
and fibrosis in nonDM SD/obese rats with spontaneous development of cardiomyopathy, without affecting plasma glucose levels, which strengthens the possibility of its use in nonDM patients [71].

Another proposed explanation is an interaction between the use of SGLT-2i and RAAS; as SGLT-2i promote volume contraction, there is an activation of RAAS through a negative feedback loop. Because there is a significant number of subjects under RAAS inhibitors in SGLT-2i trials (i.e., angiotensin-converting enzyme inhibitors or angiotensin-receptor antagonists), the combined effect of SGLT-2i and RAAS inhibitors may favor cardioprotective pathways of RAAS, with an increased production of angiotensin 1-7 and activation of both Mas and type 2 angiotensin receptor [72], with global vasodilatation, anti-inflammatory, and positive inotropic effects [67].

As mentioned above, there seems to be a link between T2DM and HF, through stimulation of NHE1 and NH3. It is curious that, though SGLT-2 is not expressed in the heart, SGLT-2i can block cardiac NH1 (which is upregulated both in HF and in T2DM [20]), resulting in attenuation of higher cytosolic $\mathrm{Na}^{+}$and $\mathrm{Ca}^{2+}$ concentrations and restored mitochondrial $\left[\mathrm{Ca}^{2+}\right]$ [67]. They also block the renal isoform $(\mathrm{NH} 3)$, further enhancing natriuresis $[19,20,52]$.

Although there is a weight reduction with these therapies through caloric loss with glycosuria of about 200 $\mathrm{kcal} /$ day [19], it seems not to be the main mechanism for the cardiovascular benefits seen as they were evident too soon after the initiation of SGLT-2i. In addition, there is a small increase in glucagon, which may have an inotropic effect and assist with appetite control [55]. They may also reduce the levels of leptin and increase adiponectin, with a reduction of epicardial fat $[19,52]$.

\section{Mechanisms of Renal Protection}

As glucose absorption in the tubular cell depends on the sodium gradient (which is maintained through the activity of the basal ATP-dependent $\mathrm{Na}^{+} / \mathrm{K}^{+}$pump), it is argued that, in $\mathrm{DM}$, the greater glucose concentration in the filtered fluid demands a higher absorption, with a consequent greater ATP and oxygen consumption, resulting in a relative local hypoxia, which may be at least partially relieved by SGLT-2i administration $[63,73,74]$. This may account for some of the renal, and even cardiovascular, benefits of this drug class.

Some experimental studies have proven that SGLT-2i exert a consistent anti-inflammatory and antifibrotic effect, which has been best described in the kidney, with attenuation of infiltration of inflammatory cells (i.e., proinflammatory macrophages), accumulation of extracellular matrix, oxidative stress, and expression of some inflammatory markers, such as MCP-1, osteopontin, RANTES, IL-6, p65, ICAM-1, PAI-1, TGF- $\beta$, CTGF, TLR4, NFkB, AP-1 binding, collagen IV expression, CCL2, CD14, TIMP2, and Nox-4 [75-82].

Another explanation is based on the fact that natriuresis stimulates the tubuloglomerular feedback, resulting in vasoconstriction of the afferent arteriole, reducing intraglomerular hypertension and preserving kidney function [52]. As there is an important relationship between HF and kidney dysfunction, SGLT-2i may break this vicious circle [19].

\section{Conclusion}

\section{Clinical Perspectives}

The cardiovascular outcome trials with SGLT-2i have changed our understanding of the association between T2DM and cardiovascular disease. More importantly, these data are changing the paradigm of T2DM management, as reflected in the recent 2019 ESC Diabetes Guidelines [83], which focus on the importance of using agents with a demonstrated reduction in cardiovascular events instead of the classic glucocentric approach.

SGLT-2i started as a new class of oral glucose-lowering drugs of only moderate efficacy in the reduction of $\mathrm{HbAlc}$ that were also capable of inducing weight loss and BP reduction without a significant risk of hypoglycemia. The recent cardiovascular outcome trials have shown that they not only markedly lower the risk of HF across the cardiovascular continuum while providing renal "protection," but they also reduce the risk of cardiovascular events in patients with atherosclerotic disease.

Recently, with demonstration of their benefits also in patients with HF with a reduced $\mathrm{EF}$, irrespectively of the presence of T2DM, a new era has started. These drugs should be viewed not only as oral antidiabetic pills but also as agents that provide cardiovascular protection. The time has come to see SGLT-2i hitting 2 birds (T2DM and HF) with a single stone.

\section{Statement of Ethics}

As this is a review article, no human or animal experiments were conducted by the authors. 


\section{Disclosure Statement}

The authors have no conflict of interests to declare.

\section{Author Contributions}

All of the authors participated in the process of bibliographic search, selection of relevant articles, typing, creation of iconography, and final review.

\section{Funding Sources}

The authors have no funding to report.

\section{References}

1 Zheng Y, Ley SH, Hu FB. Global aetiology and epidemiology of type 2 diabetes mellitus and its complications. Nat Rev Endocrinol. 2018 Feb;14(2):88-98.

2 Shah AD, Langenberg C, Rapsomaniki E, Denaxas S, Pujades-Rodriguez M, Gale CP, et al. Type 2 diabetes and incidence of cardiovascular diseases: a cohort study in 1.9 million people. Lancet Diabetes Endocrinol. 2015 Feb; 3(2):105-13.

3 US Food and Drug Administration. Guidance for industry: diabetes mellitus - evaluating cardiovascular risk in new antidiabetic therapies to treat type 2 diabetes. Silver Spring: FDA; 2008. Available from: https://www.fda. gov/regulatory-information/search-fdaguidance-documents/diabetes-mellitus-evaluating-cardiovascular-risk-new-antidiabetic-therapies-treat-type-2-diabetes.

4 Dunlay SM, Givertz MM, Aguilar D, Allen LA, Chan M, Desai AS, et al. Type 2 diabetes mellitus and heart failure: a scientific statement from the American Heart Association and Heart Failure Society of America. J Card Fail. 2019;25(8):584-619.

5 Dillmann WH. Diabetic Cardiomyopathy. Circ Res. 2019 Apr;124(8):1160-2.

6 Jia G, Hill MA, Sowers JR. Diabetic Cardiomyopathy: An Update of Mechanisms Contributing to This Clinical Entity. Circ Res. 2018 Feb;122(4):624-38.

7 Kannel WB, McGee DL. Diabetes and cardiovascular disease. The Framingham study. JAMA. 1979 May;241(19):2035-8.

8 Nichols GA, Gullion CM, Koro CE, Ephross SA, Brown JB. The incidence of congestive heart failure in type 2 diabetes: an update. Diabetes Care. 2004 Aug;27(8):1879-84.

9 Iribarren C, Karter AJ, Go AS, Ferrara A, Liu JY, Sidney S, et al. Glycemic control and heart failure among adult patients with diabetes. Circulation. 2001 Jun;103(22):2668-73.

10 Stratton IM, Adler AI, Neil HA, Matthews DR, Manley SE, Cull CA, et al. Association of glycaemia with macrovascular and microvascular complications of type 2 diabetes (UKPDS 35): prospective observational study. BMJ. 2000 Aug;321(7258):405-12.
11 Held C, Gerstein HC, Yusuf S, Zhao F, Hilbrich L, Anderson C, et al.; ONTARGET/ TRANSCEND Investigators. Glucose levels predict hospitalization for congestive heart failure in patients at high cardiovascular risk. Circulation. 2007 Mar;115(11):1371-5.

12 Fontes-Carvalho R, Ladeiras-Lopes R, Bettencourt P, Leite-Moreira A, Azevedo A. Diastolic dysfunction in the diabetic continuum: association with insulin resistance, metabolic syndrome and type 2 diabetes. Cardiovasc Diabetol. 2015 Jan;14(1):4.

13 Echouffo-Tcheugui JB, Xu H, DeVore AD, Schulte PJ, Butler J, Yancy CW, et al. Temporal trends and factors associated with diabetes mellitus among patients hospitalized with heart failure: findings from Get With The Guidelines-Heart Failure registry. Am Heart J. 2016 Dec;182:9-20.

14 Butler J, Hamo CE, Filippatos G, Pocock SJ, Bernstein RA, Brueckmann M, et al.; EMPEROR Trials Program. The potential role and rationale for treatment of heart failure with sodium-glucose co-transporter 2 inhibitors. Eur J Heart Fail. 2017 Nov;19(11):1390-400.

15 Zhou L, Deng W, Zhou L, Fang P, He D, Zhang W, et al. Prevalence, incidence and risk factors of chronic heart failure in the type 2 diabetic population: systematic review. Curr Diabetes Rev. 2009 Aug;5(3):171-84.

16 Shimizu I, Yoshida Y, Katsuno T, Tateno K, Okada S, Moriya J, et al. p53-induced adipose tissue inflammation is critically involved in the development of insulin resistance in heart failure. Cell Metab. 2012 Jan;15(1):51-64.

17 Giugliano D, Meier JJ, Esposito K. Heart failure and type 2 diabetes: from cardiovascular outcome trials, with hope. Diabetes Obes Metab. 2019 May;21(5):1081-7.

18 Marwick TH, Ritchie R, Shaw JE, Kaye D. Implications of Underlying Mechanisms for the Recognition and Management of Diabetic Cardiomyopathy. J Am Coll Cardiol. 2018 Jan;71(3):339-51.

19 Zelniker TA, Braunwald E. Cardiac and Renal Effects of Sodium-Glucose Co-Transporter 2 Inhibitors in Diabetes: JACC State-of-the-Art Review. J Am Coll Cardiol. 2018 Oct;72(15): 1845-55.
20 Packer M. Activation and Inhibition of Sodium-Hydrogen Exchanger Is a Mechanism That Links the Pathophysiology and Treatment of Diabetes Mellitus With That of Heart Failure. Circulation. 2017 Oct;136(16):154859.

21 Van Steenbergen A, Balteau M, Ginion A, Ferté L, Battault S, Ravenstein CM, et al. Sodium-myoinositol cotransporter-1, SMIT1, mediates the production of reactive oxygen species induced by hyperglycemia in the heart. Sci Rep. 2017 Jan;7(1):41166.

22 Hsia DS, Grove O, Cefalu WT. An update on sodium-glucose co-transporter-2 inhibitors for the treatment of diabetes mellitus. Curr Opin Endocrinol Diabetes Obes. 2017 Feb; 24(1):73-9.

23 Yang XP, Lai D, Zhong XY, Shen HP, Huang YL. Efficacy and safety of canagliflozin in subjects with type 2 diabetes: systematic review and meta-analysis. Eur J Clin Pharmacol. 2014 Oct; 70(10):1149-58.

24 Zhang M, Zhang L, Wu B, Song H, An Z, Li S. Dapagliflozin treatment for type 2 diabetes: a systematic review and meta-analysis of randomized controlled trials. Diabetes Metab Res Rev. 2014 Mar;30(3):204-21.

25 Liakos A, Karagiannis T, Athanasiadou E, Sarigianni M, Mainou M, Papatheodorou K, et al. Efficacy and safety of empagliflozin for type 2 diabetes: a systematic review and metaanalysis. Diabetes Obes Metab. 2014 Oct; 16(10):984-93.

26 Zinman B, Wanner C, Lachin JM, Fitchett D, Bluhmki E, Hantel S, et al.; EMPA-REG OUTCOME Investigators. Empagliflozin, Cardiovascular Outcomes, and Mortality in Type 2 Diabetes. N Engl J Med. 2015 Nov; 373(22):2117-28.

27 Neal B, Perkovic V, Mahaffey KW, de Zeeuw D, Fulcher G, Erondu N, et al.; CANVAS Program Collaborative Group. Canagliflozin and cardiovascular and renal events in type 2 diabetes. N Engl J Med. 2017 Aug;377(7):644-57.

28 Wiviott SD, Raz I, Bonaca MP, Mosenzon O, Kato ET, Cahn A, et al.; DECLARE-TIMI 58 Investigators. Dapagliflozin and Cardiovascular Outcomes in Type 2 Diabetes. N Engl J Med. 2019 Jan;380(4):347-57. 
29 Zelniker TA, Wiviott SD, Raz I, Im K, Goodrich EL, Bonaca MP, et al. SGLT2 inhibitors for primary and secondary prevention of cardiovascular and renal outcomes in type 2 diabetes: a systematic review and meta-analysis of cardiovascular outcome trials. Lancet. 2019 Jan;393(10166):31-9.

30 Furtado RH, Bonaca MP, Raz I, Zelniker TA, Mosenzon O, Cahn A, et al. Dapagliflozin and cardiovascular outcomes in patients with type 2 diabetes mellitus and previous myocardial infarction. Circulation. 2019 May;139(22): 2516-27.

31 Fitchett D, Butler J, van de Borne P, Zinman B, Lachin JM, Wanner C, et al.; EMPA-REG OUTCOME $^{\circledR}$ trial investigators. Effects of empagliflozin on risk for cardiovascular death and heart failure hospitalization across the spectrum of heart failure risk in the EMPAREG OUTCOME ${ }^{\circledR}$ trial. Eur Heart J. 2018 Feb;39(5):363-70.

32 Lin AH, Chin JC, Sicignano NM, Evans AM. Repeat Hospitalizations Predict Mortality in Patients With Heart Failure. Mil Med. 2017 Sep;182(9):e1932-7.

33 Savarese G, Sattar N, Januzzi J, Verma S, Lund LH, Fitchett D, et al. Empagliflozin Is Associated With a Lower Risk of Post-Acute Heart Failure Rehospitalization and Mortality. Circulation. 2019 Mar;139(11):1458-60.

34 Kato ET, Silverman MG, Mosenzon O, Zelniker TA, Cahn A, Furtado RH, et al. Effect of Dapagliflozin on Heart Failure and Mortality in Type 2 Diabetes Mellitus. Circulation. 2019 May;139(22):2528-36.

35 McMurray JJ, Solomon SD, Inzucchi SE, Køber L, Kosiborod MN, Martinez FA, et al.; DAPA-HF Trial Committees and Investigators. Dapagliflozin in Patients with Heart Failure and Reduced Ejection Fraction. N Engl J Med. 2019 Nov;381(21):1995-2008.

36 Patorno E, Pawar A, Franklin JM, Najafzadeh M, Déruaz-Luyet A, Brodovicz KG, et al. Empagliflozin and the Risk of Heart Failure Hospitalization in Routine Clinical Care. Circulation. 2019 Jun;139(25):2822-30.

37 Kosiborod M, Cavender MA, Fu AZ, Wilding JP, Khunti K, Holl RW, et al.; CVD-REAL Investigators and Study Group. Lower Risk of Heart Failure and Death in Patients Initiated on Sodium-Glucose Cotransporter-2 Inhibitors Versus Other Glucose-Lowering Drugs: The CVD-REAL Study (Comparative Effectiveness of Cardiovascular Outcomes in New Users of Sodium-Glucose Cotransporter-2 Inhibitors). Circulation. 2017 Jul;136(3):24959.

38 Cavender MA, Norhammar A, Birkeland KI, Jørgensen ME, Wilding JP, Khunti K, et al.; CVD-REAL Investigators and Study Group. SGLT-2 Inhibitors and Cardiovascular Risk: an Analysis of CVD-REAL. J Am Coll Cardiol. 2018 Jun;71(22):2497-506.
39 Kosiborod M, Birkeland KI, Cavender MA, Fu AZ, Wilding JP, Khunti K, et al.; CVD-REAL Investigators and Study Group. Rates of myocardial infarction and stroke in patients initiating treatment with SGLT2-inhibitors versus other glucose-lowering agents in realworld clinical practice: results from the CVDREAL study. Diabetes Obes Metab. 2018 Aug; 20(8): 1983-7.

40 Birkeland KI, Jørgensen ME, Carstensen B, Persson F, Gulseth HL, Thuresson M, et al. Cardiovascular mortality and morbidity in patients with type 2 diabetes following initiation of sodium-glucose co-transporter-2 inhibitors versus other glucose-lowering drugs (CVD-REAL Nordic): a multinational observational analysis. Lancet Diabetes Endocrinol. 2017 Sep;5(9):709-17.

41 Kosiborod M, Lam CS, Kohsaka S, Kim DJ, Karasik A, Shaw J, et al.; CVD-REAL Investigators and Study Group. Cardiovascular Events Associated With SGLT-2 Inhibitors Versus Other Glucose-Lowering Drugs: the CVD-REAL 2 Study. J Am Coll Cardiol. 2018 Jun;71(23):2628-39.

42 Perkovic V, Jardine MJ, Neal B, Bompoint S, Heerspink HJ, Charytan DM, et al.; CREDENCE Trial Investigators. Canagliflozin and renal outcomes in type 2 diabetes and nephropathy. N Engl J Med. 2019 Jun;380(24): 2295-306.

43 Tahara A, Takasu T, Yokono M, Imamura M, Kurosaki E. Characterization and comparison of sodium-glucose cotransporter 2 inhibitors in pharmacokinetics, pharmacodynamics, and pharmacologic effects. J Pharmacol Sci. 2016 Mar;130(3):159-69.

44 Tahara A, Takasu T, Yokono M, Imamura M, Kurosaki E. Characterization and comparison of sodium-glucose cotransporter 2 inhibitors: Part 2. Antidiabetic effects in type 2 diabetic mice. J Pharmacol Sci. 2016 Jul;131(3): 198-208.

45 Tahara A, Takasu T, Yokono M, Imamura M, Kurosaki E. Characterization and comparison of SGLT2 inhibitors. Part 3: effects on diabetic complications in type 2 diabetic mice. Eur J Pharmacol. 2017 Aug;809:163-71.

46 Suzuki M, Honda K, Fukazawa M, Ozawa K, Hagita H, Kawai T, et al. Tofogliflozin, a potent and highly specific sodium/glucose cotransporter 2 inhibitor, improves glycemic control in diabetic rats and mice. J Pharmacol Exp Ther. 2012 Jun;341(3):692-701.

47 Yanai $\mathrm{H}$, Hakoshima M, Adachi $\mathrm{H}$. What Properties of Sodium-Glucose Cotransporter 2 Inhibitors Determine the Improvement in Hemoglobin Alc and Body Weight? J Clin Med Res. 2017 May;9(5):446-8.

48 Scheen AJ. Pharmacokinetic and pharmacodynamic profile of empagliflozin, a sodium glucose co-transporter 2 inhibitor. Clin Pharmacokinet. 2014 Mar;53(3):213-25.
49 Takebayashi K, Inukai T. Effect of Sodium Glucose Cotransporter 2 Inhibitors With Low SGLT2/SGLT1 Selectivity on Circulating Glucagon-Like Peptide 1 Levels in Type $2 \mathrm{Di}$ abetes Mellitus. J Clin Med Res. 2017 Sep;9(9): 745-53.

50 Inzucchi SE, Fitchett D, Wanner C, George J, Woerle HJ, Zinman B. Reduction in cardiovascular death with empagliflozin is consistent across categories of baseline $\mathrm{HbAlc}$ and change in HbAlc: results from EMPA-REG OUTCOME. Diabetologie Stoffwechsel. 2018;13:151.

51 Wanner C, Lachin JM, Inzucchi SE, Fitchett D, Mattheus M, George J, et al.; EMPA-REG OUTCOME Investigators. Empagliflozin and clinical outcomes in patients with type 2 diabetes mellitus, established cardiovascular disease, and chronic kidney disease. Circulation. 2018 Jan;137(2):119-29.

52 Verma S, McMurray JJ. SGLT2 inhibitors and mechanisms of cardiovascular benefit: a stateof-the-art review. Diabetologia. 2018 Oct; 61(10):2108-17.

53 Inzucchi SE, Zinman B, Fitchett D, Wanner C, Ferrannini E, Schumacher M, et al. How Does Empagliflozin Reduce Cardiovascular Mortality? Insights From a Mediation Analysis of the EMPA-REG OUTCOME Trial. Diabetes Care. 2018 Feb;41(2):356-63.

54 Hallow KM, Helmlinger G, Greasley PJ, McMurray JJ, Boulton DW. Why do SGLT2 inhibitors reduce heart failure hospitalization? A differential volume regulation hypothesis. Diabetes Obes Metab. 2018 Mar;20(3):479-87.

55 Bailey CJ, Marx N. Cardiovascular protection in type 2 diabetes: insights from recent outcome trials. Diabetes Obes Metab. 2019 Jan; 21(1):3-14.

56 Scheen AJ. Reappraisal of the diuretic effect of empagliflozin in the EMPA-REG OUTCOME trial: comparison with classic diuretics. Diabetes Metab. 2016 Sep;42(4):224-33.

57 Baker WL, Smyth LR, Riche DM, Bourret EM, Chamberlin KW, White WB. Effects of sodium-glucose co-transporter 2 inhibitors on blood pressure: a systematic review and metaanalysis. J Am Soc Hypertens. 2014 Apr;8(4): 262-75.e9.

58 Sha S, Polidori D, Heise T, Natarajan J, Farrell $\mathrm{K}$, Wang SS, et al. Effect of the sodium glucose co-transporter 2 inhibitor canagliflozin on plasma volume in patients with type 2 diabetes mellitus. Diabetes Obes Metab. 2014 Nov; 16(11):1087-95.

59 Leimbach WN Jr, Wallin BG, Victor RG, Aylward PE, Sundlöf G, Mark AL. Direct evidence from intraneural recordings for increased central sympathetic outflow in patients with heart failure. Circulation. 1986 May;73(5):913-9.

60 Vazir A, Claggett B, Pitt B, Anand I, Sweitzer $\mathrm{N}$, Fang J, et al. Prognostic Importance of Temporal Changes in Resting Heart Rate in Heart Failure and Preserved Ejection Fraction: from the TOPCAT Study. JACC Heart Fail. 2017 Nov;5(11):782-91. 
61 Hillis GS, Hata J, Woodward M, Perkovic V, Arima $\mathrm{H}$, Chow $\mathrm{CK}$, et al. Resting heart rate and the risk of microvascular complications in patients with type 2 diabetes mellitus. J Am Heart Assoc. 2012 Oct;1(5):e002832.

62 Sano M, Chen S, Imazeki H, Ochiai H, Seino $\mathrm{Y}$. Changes in heart rate in patients with type 2 diabetes mellitus after treatment with luseogliflozin: subanalysis of placebo-controlled, double-blind clinical trials. J Diabetes Investig. 2018 May;9(3):638-41.

63 Sano M. A new class of drugs for heart failure: SGLT2 inhibitors reduce sympathetic overactivity. J Cardiol. 2018 May;71(5):471-6.

64 Verma S, Rawat S, Ho KL, Wagg CS, Zhang L, Teoh H, et al. Empagliflozin increases cardiac energy production in diabetes: novel translational insights into the heart failure benefits of SGLT2 inhibitors. JACC Basic Transl Sci. 2018 Aug;3(5):575-87.

65 Santos-Gallego CG, Ibanez JA, Antonio RS, Ishikawa K, Watanabe S, Picatoste Botija MB, et al. Empagliflozin induces a myocardial metabolic shift from glucose consumption to ketone metabolism that mitigates adverse cardiac remodeling and improves myocardial contractility. J Am Coll Cardiol. 2018; 71(11):A674.

66 Kappel BA, Lehrke M, Schütt K, Artati A, Adamski J, Lebherz C, et al. Effect of empagliflozin on the metabolic signature of patients with type 2 diabetes mellitus and cardiovascular disease. Circulation. 2017 Sep; 136(10):969-72.

67 Filippatos TD, Liontos A, Papakitsou I, Elisaf MS. SGLT2 inhibitors and cardioprotection: a matter of debate and multiple hypotheses. Postgrad Med. 2019 Mar;131(2):82-8.

68 Li C, Zhang J, Xue M, Li X, Han F, Liu X, et al. SGLT2 inhibition with empagliflozin attenuates myocardial oxidative stress and fibrosis in diabetic mice heart. Cardiovasc Diabetol. 2019 Feb;18(1):15.
69 Verma S, McMurray JJ. The Serendipitous Story of SGLT2 Inhibitors in Heart Failure. Circulation. 2019 May;139(22):2537-41.

70 Adingupu DD, Göpel SO, Grönros J, Behrendt M, Sotak M, Miliotis T, et al. SGLT2 inhibition with empagliflozin improves coronary microvascular function and cardiac contractility in prediabetic ob/ob-/- mice. Cardiovasc Diabetol. 2019 Feb;18(1):16.

71 Takasu T, Takakura S. Effect of ipragliflozin, an SGLT2 inhibitor, on cardiac histopathological changes in a non-diabetic rat model of cardiomyopathy. Life Sci. 2019 Aug;230:1927.

72 Muskiet MH, van Raalte DH, van Bommel EJ, Smits MM, Tonneijck L. Understanding EMPA-REG OUTCOME. Lancet Diabetes Endocrinol. 2015 Dec;3(12):928-9.

73 Körner A, Eklöf AC, Celsi G, Aperia A. Increased renal metabolism in diabetes. Mechanism and functional implications. Diabetes. 1994 May;43(5):629-33.

74 Gilbert RE. SGLT2 inhibitors: $\beta$ blockers for the kidney? Lancet Diabetes Endocrinol. 2016 Oct;4(10):814.

75 Shin SJ, Chung S, Kim SJ, Lee EM, Yoo YH, Kim JW, et al. Effect of Sodium-Glucose CoTransporter 2 Inhibitor, Dapagliflozin, on Renal Renin-Angiotensin System in an Animal Model of Type 2 Diabetes. PLoS One. 2016 Nov; 11(11):e0165703.

76 Gembardt F, Bartaun C, Jarzebska N, Mayoux E, Todorov VT, Hohenstein B, et al. The SGLT2 inhibitor empagliflozin ameliorates early features of diabetic nephropathy in BTBR ob/ob type 2 diabetic mice with and without hypertension. Am J Physiol Renal Physiol. 2014 Aug;307(3):F317-25.

77 Vallon V, Gerasimova M, Rose MA, Masuda T, Satriano J, Mayoux E, et al. SGLT2 inhibitor empagliflozin reduces renal growth and albuminuria in proportion to hyperglycemia and prevents glomerular hyperfiltration in diabetic Akita mice. Am J Physiol Renal Physiol. 2014 Jan;306(2):F194-204.
78 Panchapakesan U, Pegg K, Gross S, Komala MG, Mudaliar H, Forbes J, et al. Effects of SGLT2 inhibition in human kidney proximal tubular cells-renoprotection in diabetic nephropathy? PLoS One. 2013;8(2):e54442.

79 Ojima A, Matsui T, Nishino Y, Nakamura N, Yamagishi S. Empagliflozin, an inhibitor of sodium-glucose cotransporter 2 exerts antiinflammatory and antifibrotic effects on experimental diabetic nephropathy partly by suppressing AGEs-receptor axis. Horm Metab Res. 2015;47(9):686-92.

80 Terami N, Ogawa D, Tachibana H, Hatanaka T, Wada J, Nakatsuka A, et al. Long-term treatment with the sodium glucose cotransporter 2 inhibitor, dapagliflozin, ameliorates glucose homeostasis and diabetic nephropathy in $\mathrm{db} / \mathrm{db}$ mice. PLoS One. 2014 Jun; 9(6):e100777.

81 Kawanami D, Matoba K, Takeda Y, Nagai Y, Akamine T, Yokota T, et al. SGLT2 Inhibitors as a Therapeutic Option for Diabetic Nephropathy. Int J Mol Sci. 2017 May; 18(5):E1083.

82 Wang XX, Levi J, Luo Y, Myakala K, HermanEdelstein M, Qiu L, et al. SGLT2 protein expression is increased in human diabetic nephropathy: SGLT2 protein inhibition decreases renal lipid accumulation, inflammation, and the development of nephropathy in diabetic mice. J Biol Chem. 2017 Mar;292(13):5335-48.

83 Grant PJ, Cosentino F. The 2019 ESC Guidelines on diabetes, pre-diabetes, and cardiovascular diseases developed in collaboration with the EASD: New features and the 'Ten Commandments' of the 2019 Guidelines are discussed by Professor Peter J. Grant and Professor Francesco Cosentino, the Task Force chairmen. Eur Heart J. 2019 Oct;40(39): 3215-7. 